\title{
Discrete sample introduction module (DSIM) for quantitative and isotopic analysis of methane and other gases by cavity ring-down spectroscopy
}

John W. Pohlman ${ }^{1}$, Michael Casso ${ }^{1}$, Cédric Magen ${ }^{2}$ and Emile Bergeron ${ }^{1}$

1: U.S. Geological Survey, Woods Hole Coastal \& Marine Science Center, Woods Hole MA, 02543, USA

2: University of Maryland Center for Environmental Science, Chesapeake Biological Lab, Solomons MD, 20688, USA

Supporting Information (22 Pages)

Figure S1. DSIM external components

Figure S2. Sample Processing Flowchart

Figure S3. DSIM System Purge diagram

Figure S4. DSIM System Load diagram

Figure S5. DSIM System Analysis diagram

Figure S6. DSIM Loop A Load diagram

Figure S7. DSIM Loop B Load diagram

Figure S8. DSIM Loop A Analysis diagram

Figure S9. DSIM Loop B Analysis diagram

Figure S10. DSIM Loop A Analysis (with Expansion) diagram

Figure S11. DSIM Standard Analysis diagram

Figure S12. Analysis of samples introduced by Loop B with and without the bypass line activated

Figure S13. DSIM-CRDS $\delta^{13} \mathrm{C}$ standardization for $\mathrm{CO}_{2}$ 
Figure S14. $\mathrm{CO}_{2}$ concentration standardization for DSIM sample introduction modes

Figure S15. Baseline drift for methane and $\mathrm{CO}_{2}$ for the different DSIM analysis modes

Figure S16. Low methane concentration standardization

Figure S17. Bland-Altman analysis of DSIM-CRDS and IRMS method results.

Figure S18. Ocean water sample collection and processing for DSIM-CRDS analysis

Table S1. System Configuration Table

Table S2. DSIM-CRDS $\delta^{13} \mathrm{C}-\mathrm{CH}_{4}$ standardization data 


\section{DSIM External Components}

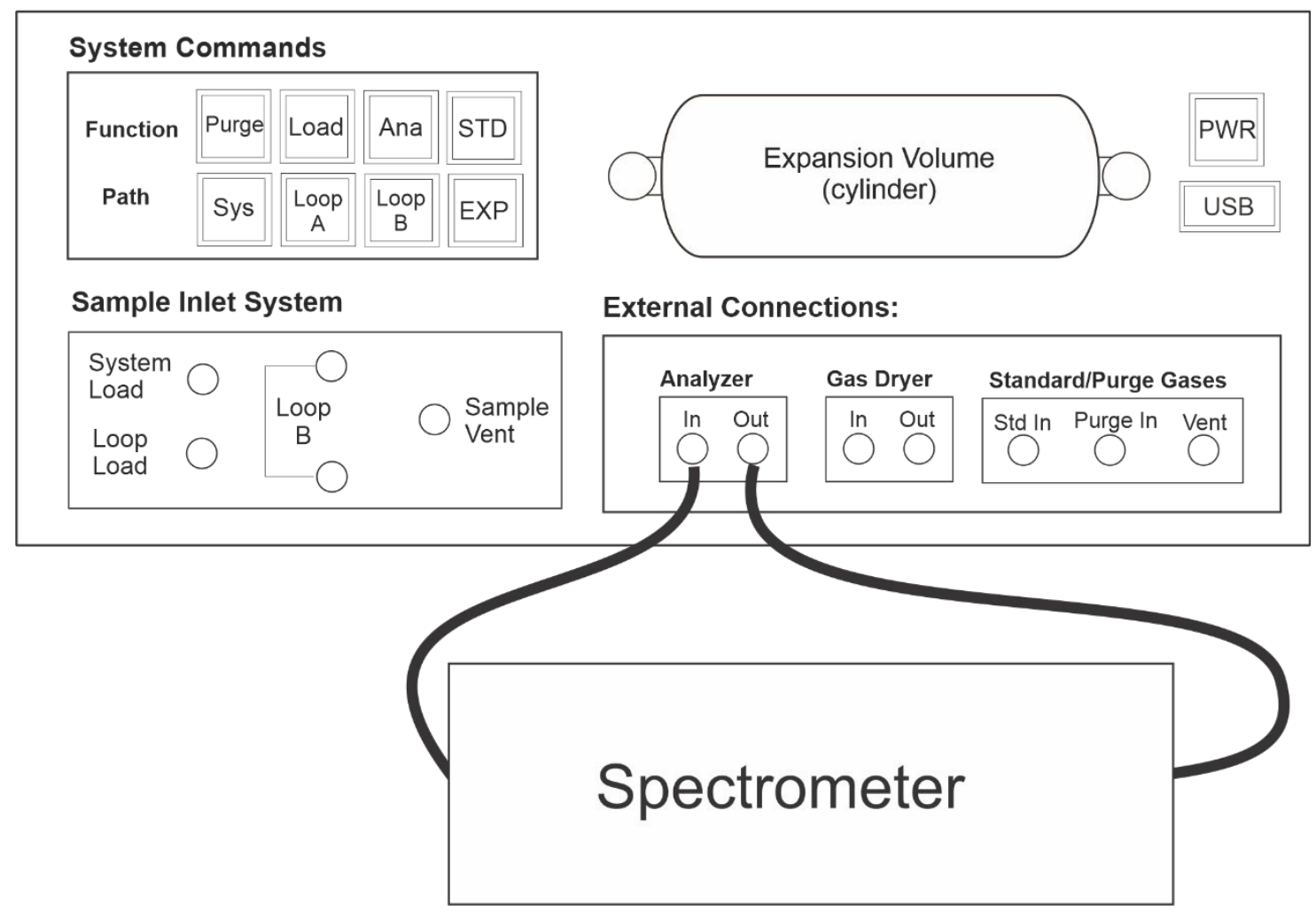

Figure S1. DSIM external components. Buttons activate system commands that control operations and determine active flow paths. The commands may also be activated by an external computer through the USB port or alternate port to control a micro-controller and/or other voltage regulating electronics. The Sample Inlet System includes ports for introducing samples into DSIM for dilution (Loop Load) and non-dilution (System Load) applications. Fittings for Loop B allow the user to connect external sample loops of differing volumes to achieve a range of sample dilution factors. The sample vent allows gas displaced during sample loading to exhaust. The expansion volume is an optionally utilized component of the analytical path that increases system volume and, therefore, dilution. Additional external connections are the inlet (In) and outlet (Out) for sample gas recirculating between DSIM and the gas analyzing spectrometer, drying gas that recirculates between the external desiccant (not shown) and the DSIM-internal Nafion ${ }^{\text {TM }}$ dryer, as well as ports for a standard gas (Std In), Purge/Carrier gas (Purge In) and system exhaust (Vent). System Command abbreviations: Ana = Analyze; STD = Standard; Sys = System; EXP = Expansion. 


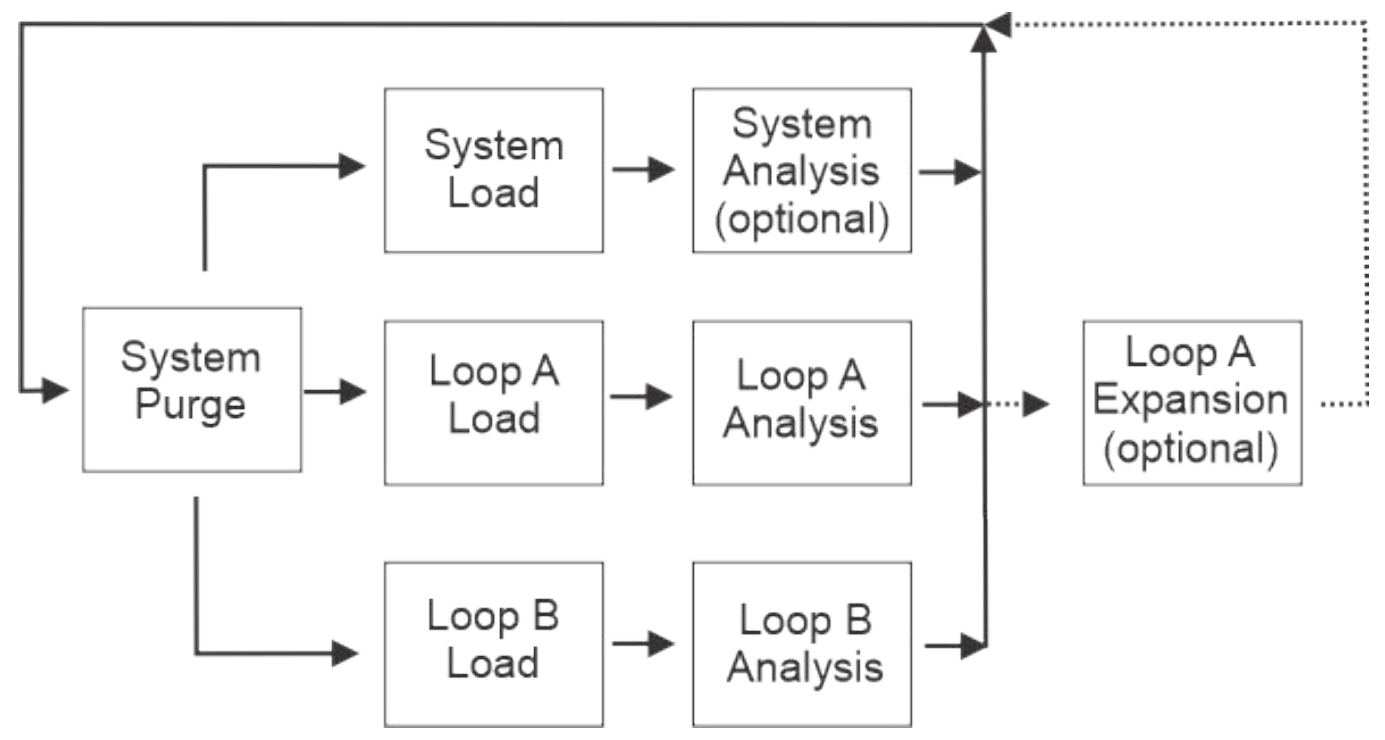

Figure S2. Sample Processing Flowchart. Each analysis is initiated with a system purge to flush analyte from the system. Following System Purge, samples that do not require dilution are introduced to DSIM during System Load and measured while the sample loads or when it recirculates during System Analysis (top path). To dilute samples exceeding the gas analyzer's operational range, small sample volumes are introduced through a fixed low-volume ( 100 $\mathrm{ml}$ ) Loop A or an exchangeable larger-volume (1-10 ml) Loop B followed by Loop A Analysis or Loop B Analysis. For cases where greater sample dilution within Loop A is required (e.g., analyte concentration > 50\%), Loop A Expansion is enabled (dashed line). 


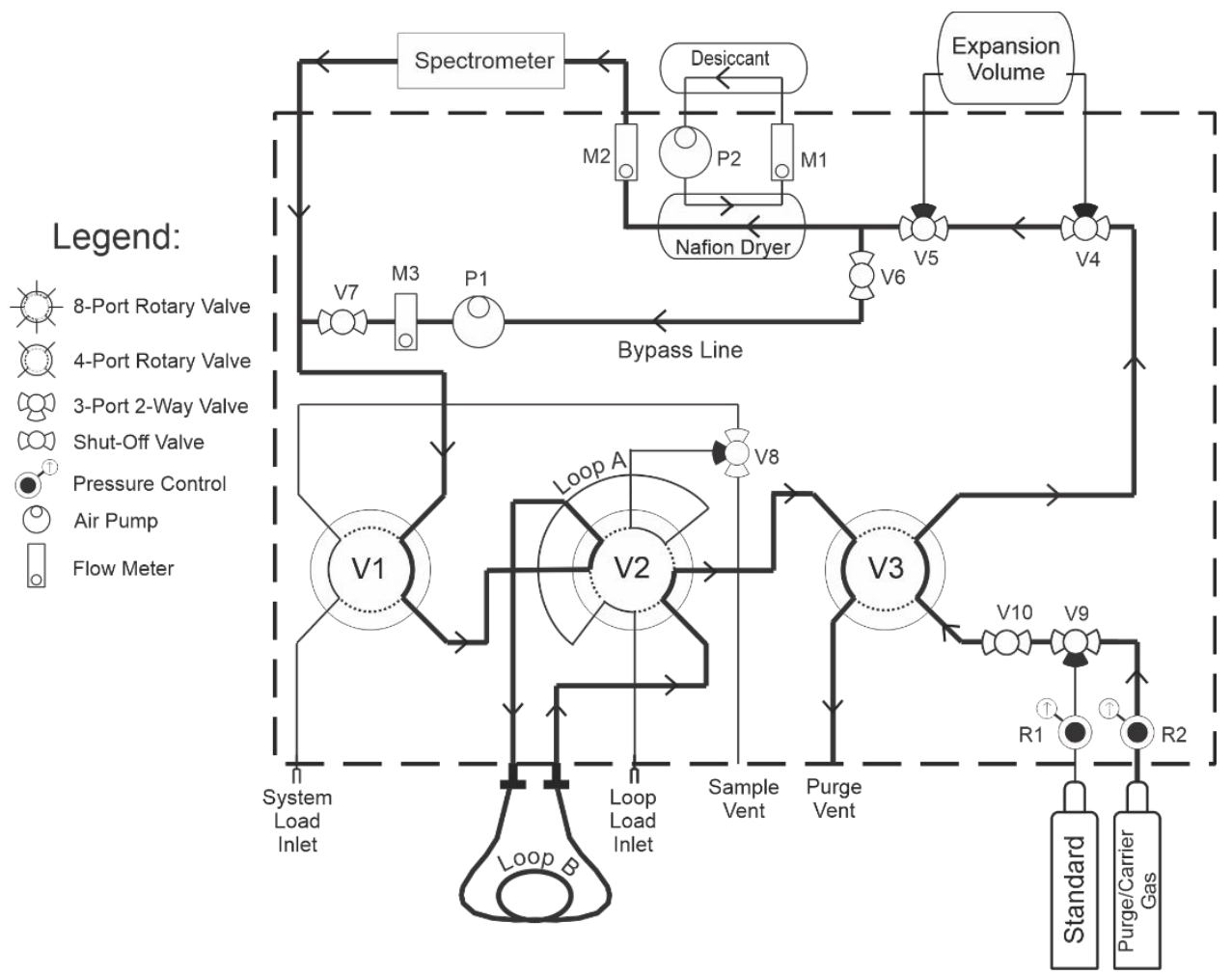

Figure S3. System Purge. Before analysis of each sample, an analyte-free purge gas flushes the previous sample from the analytical path. The purge path is depicted by the thick line. In this configuration Loop $B$ is being purged. Alternate configurations (not pictured) purge Loop $A$ and the Expansion Volume. After System Purge, the purge gas serves as the carrier gas for Loop A and Loop B Analysis operations. 


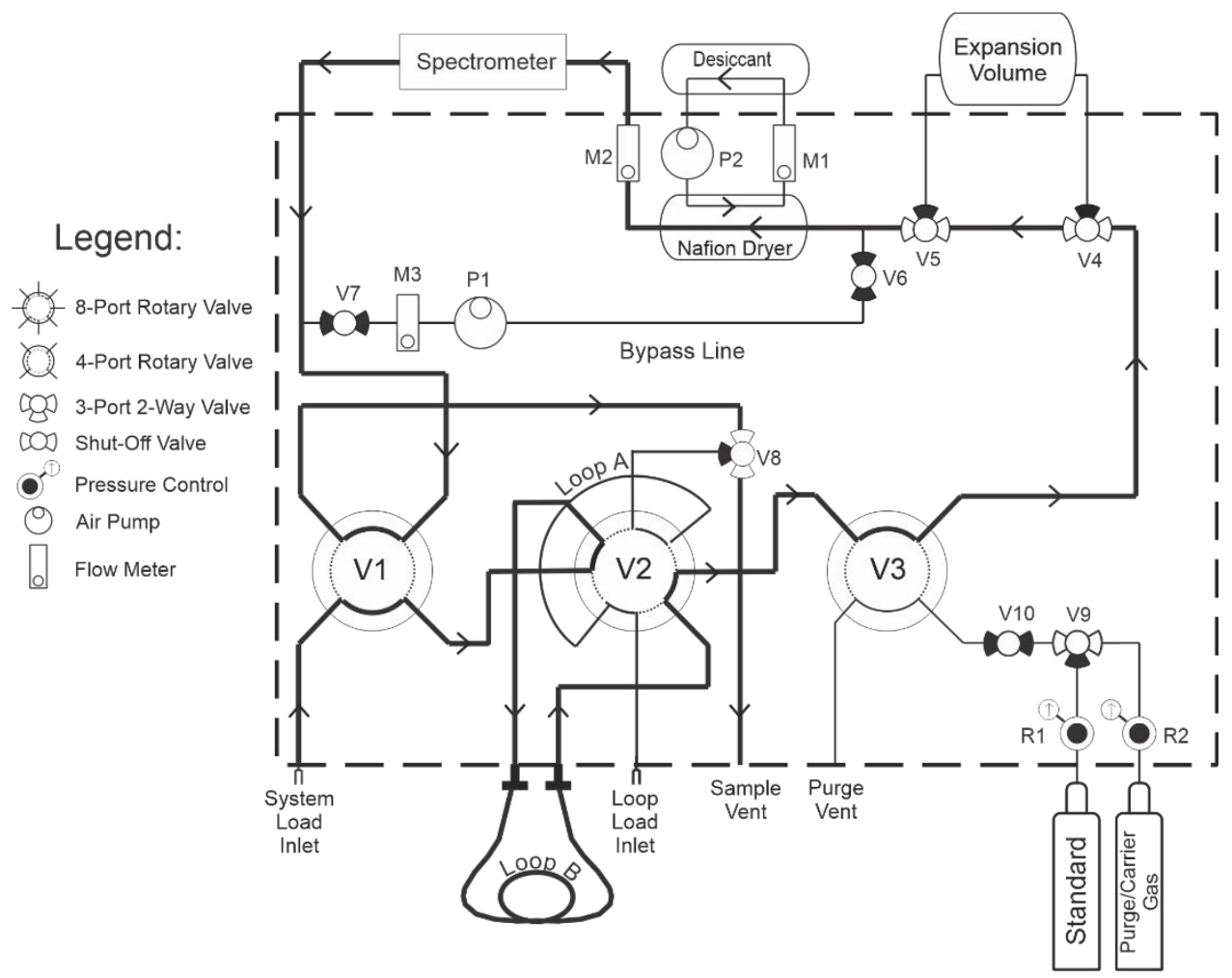

Figure S4. System Load. The gas sample is introduced into DSIM through the System Load Inlet. Samples with volumes sufficient to completely fill the analytical path to be analyzed without dilution. The flow path for System Load is depicted by the thick line. 


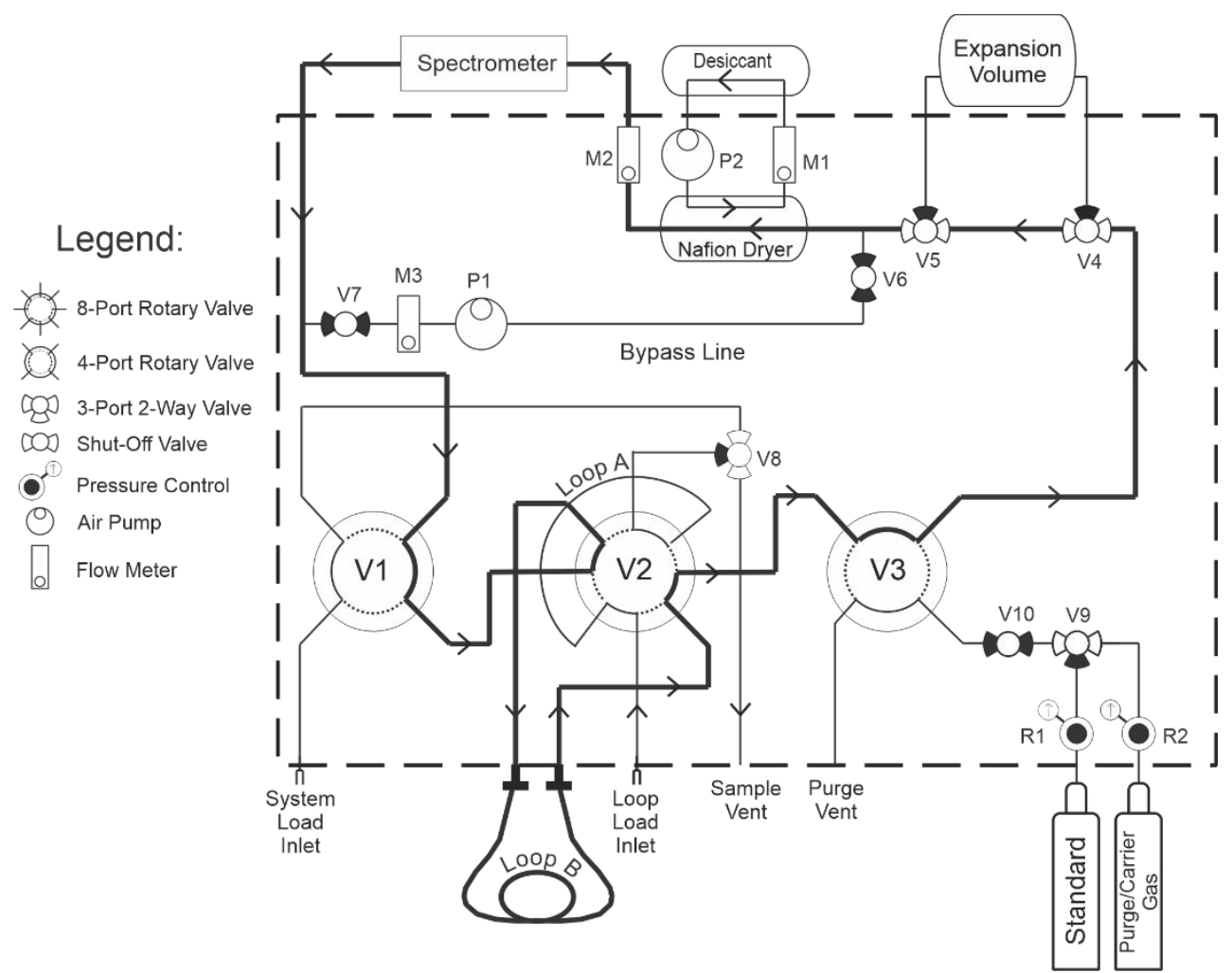

Figure S5. System Analysis. The gas sample introduced during System Load is recirculated within the analytical path without dilution. The analytical path is depicted by the thick line. 


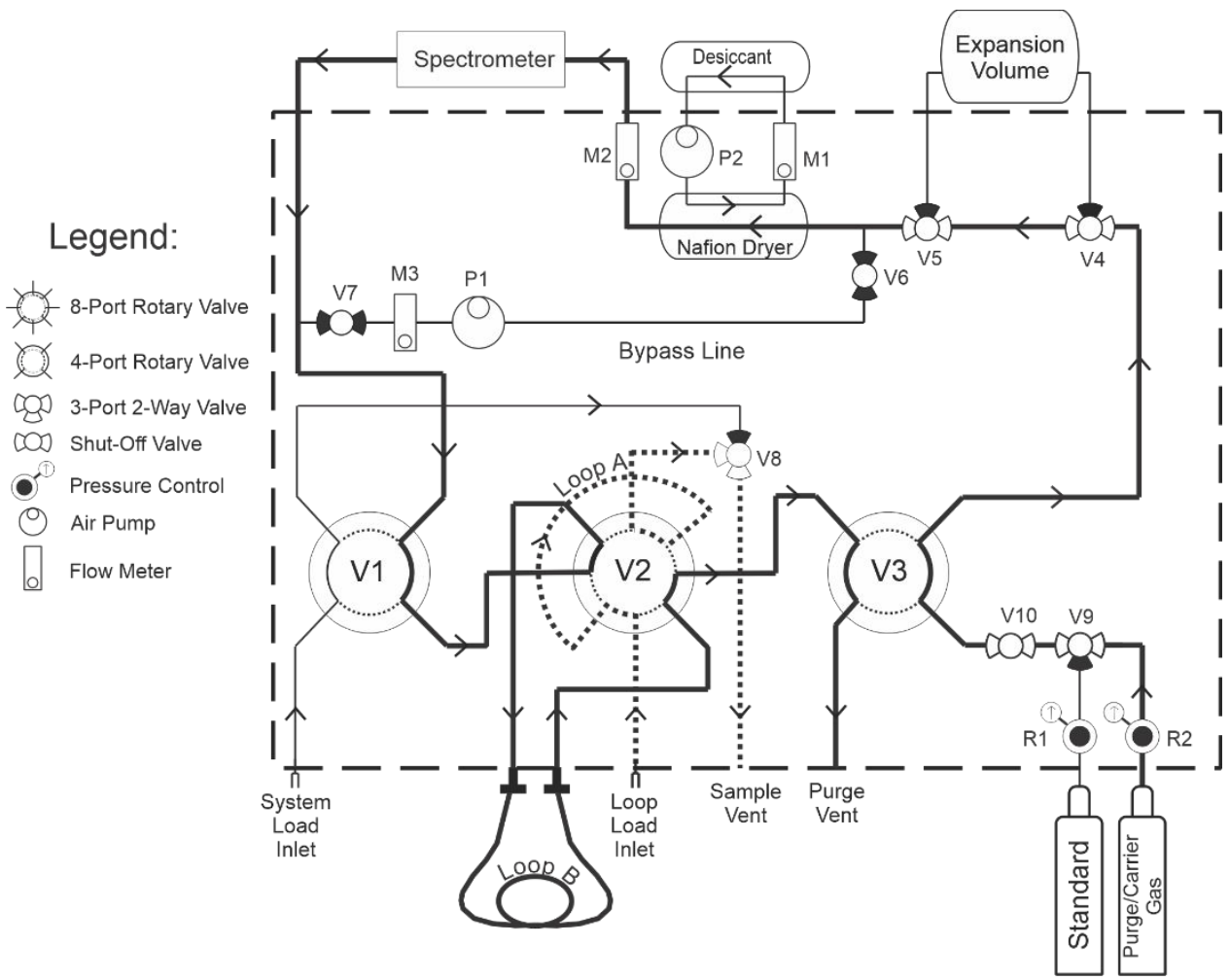

Figure S6. Loop A Load. The discrete gas sample is introduced through the Loop Load Inlet, fills Loop A and is expelled through the Sample Vent (dashed line). Meanwhile, purge gas flushes the analytical path (thick line). 


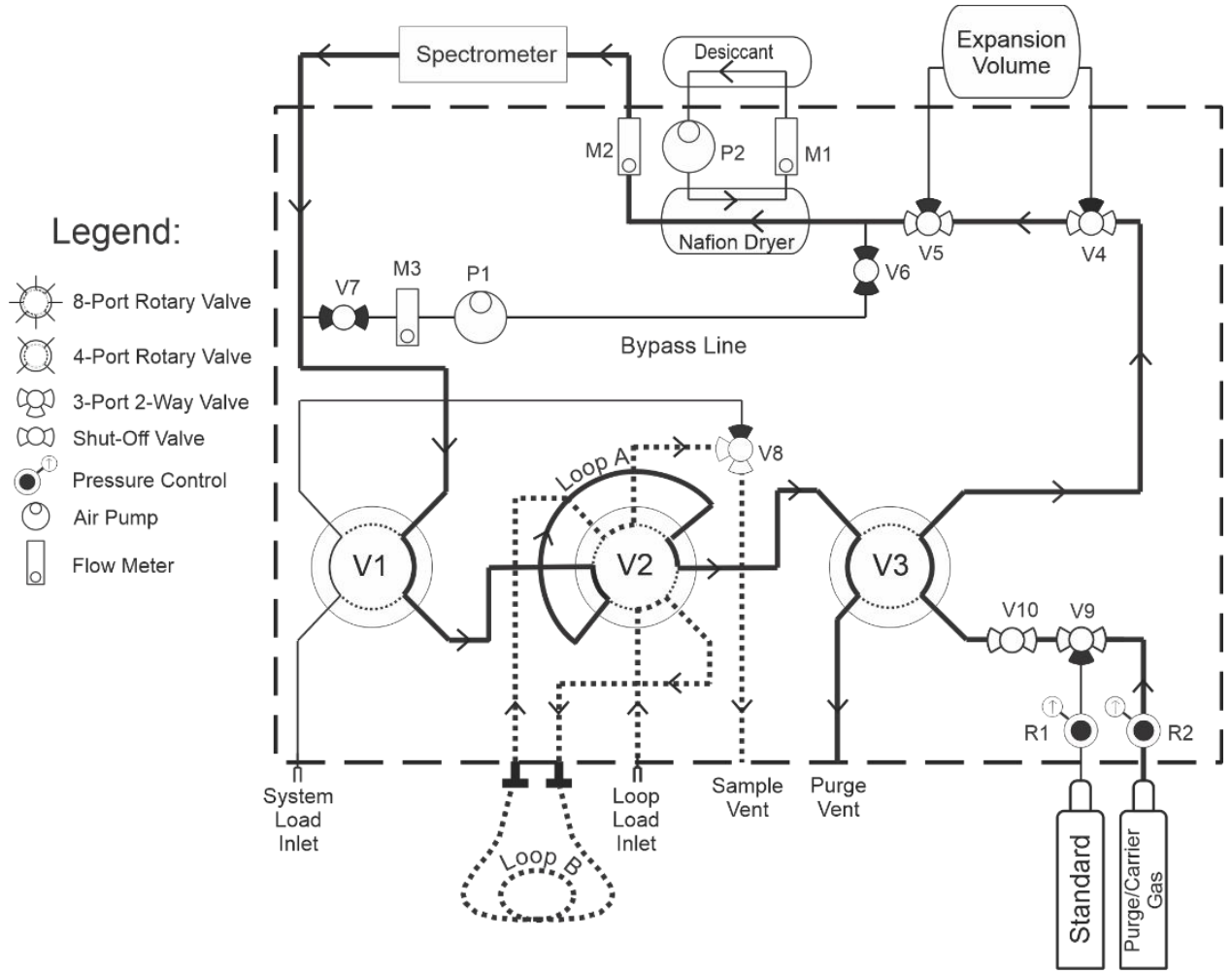

Figure S7. Loop B Load. The discrete gas sample is introduced through the Loop Load Inlet, fills Loop B and is expelled through the Sample Vent (dashed line). Meanwhile, purge gas flushes the analytical path (thick line). 


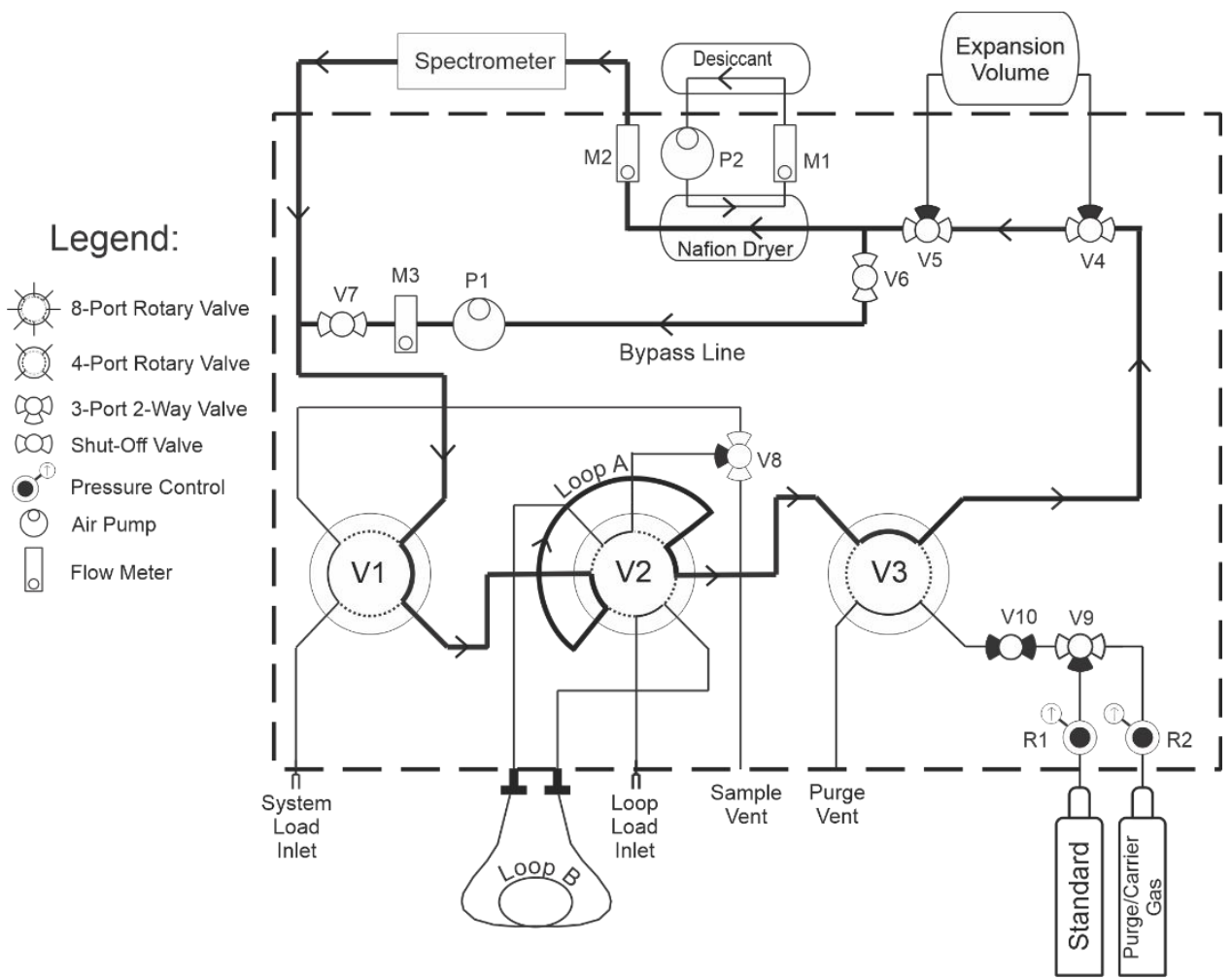

Figure S8. Loop A Analysis. The gas sample introduced during Loop A Load is recirculated and diluted within the analytical path. The Bypass Line facilitates mixing. The analytical path is depicted by the thick line. 


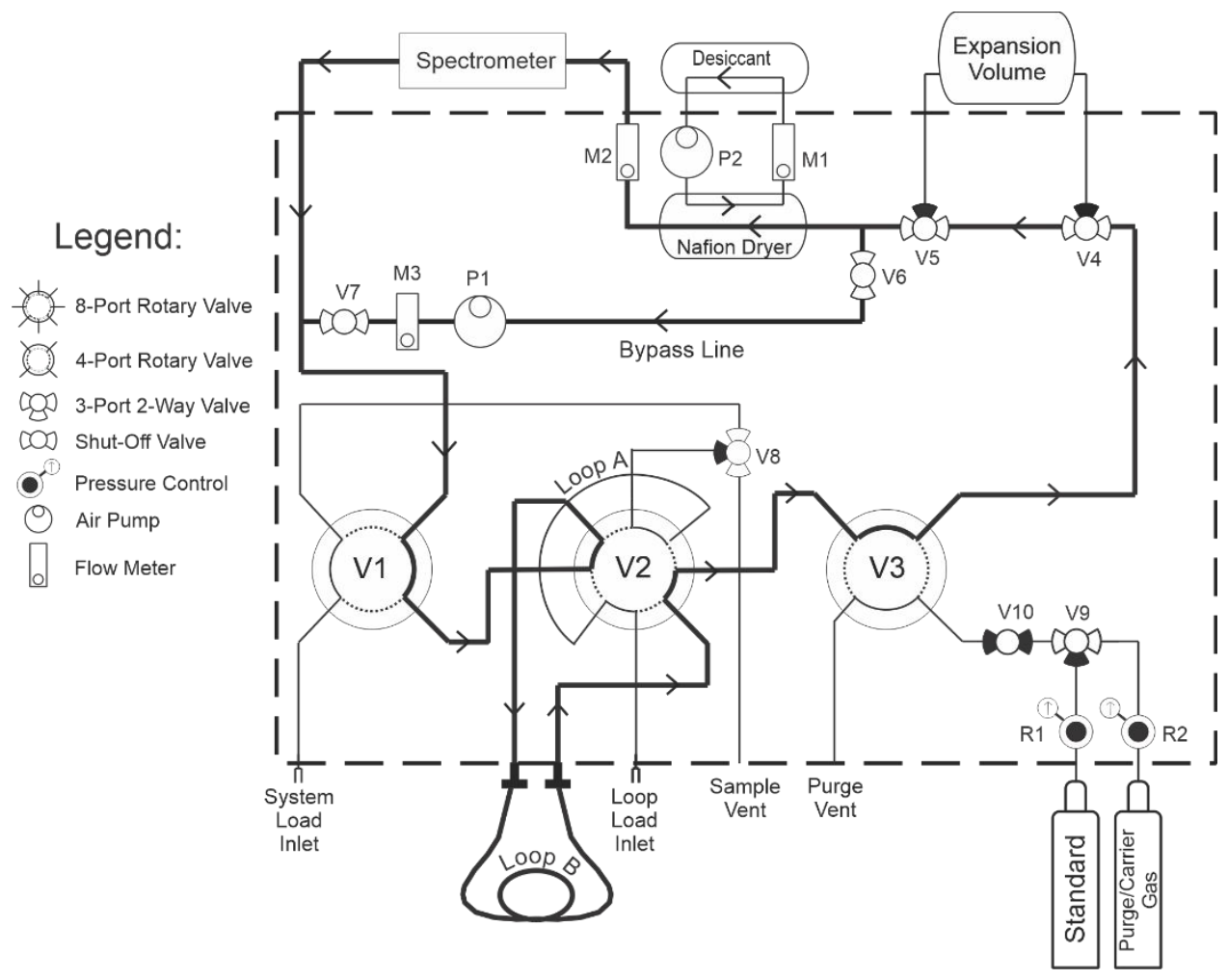

Figure S9. Loop B Analysis. The gas sample introduced during Loop B Load is recirculated and diluted within the analytical path. The Bypass Line facilitates mixing. The analytical path is depicted by the thick line. 


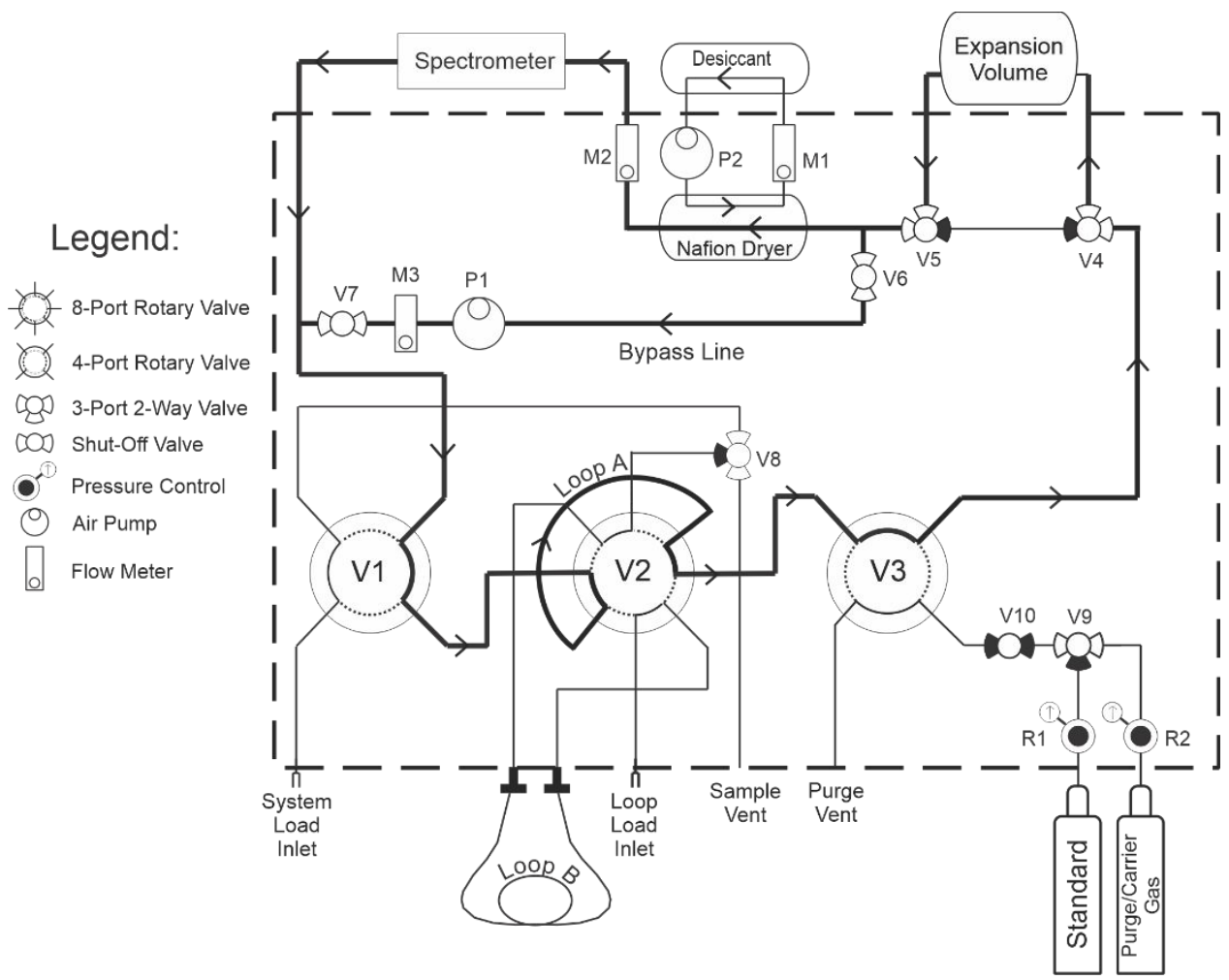

Figure S10. Loop A Analysis (with Expansion). The gas sample introduced during Loop A Load is recirculated and diluted within the analytical path. The Bypass Line facilitates mixing. When maximum dilution is required, the Expansion Volume is incorporated into the analytical path. The analytical path with the Expansion Volume enabled is depicted by the thick line. 


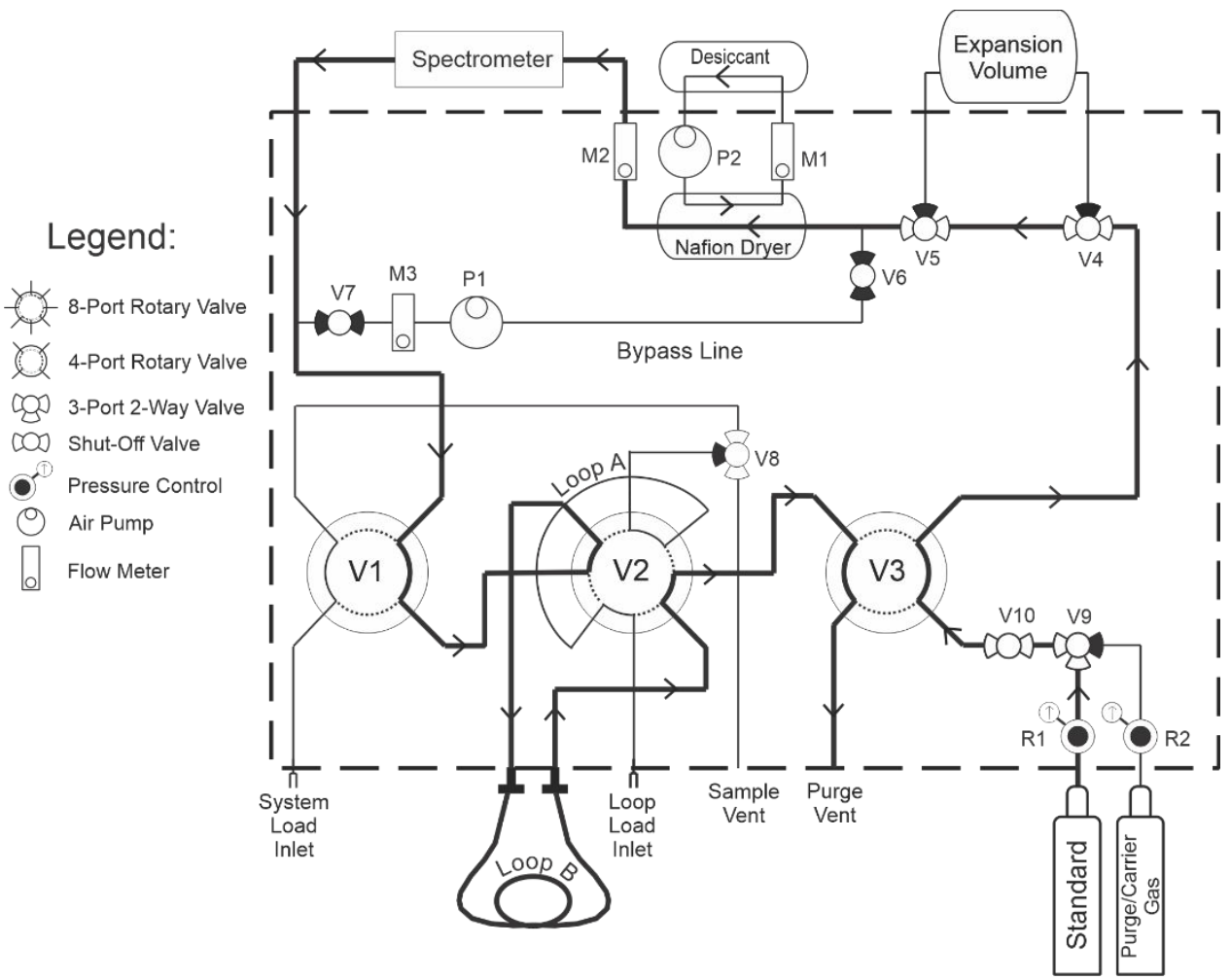

Figure S11. Standard Analysis. A target standard is delivered directly to the analyzer for monitoring instrument performance. The analytical path for the target standard is depicted by the thick line. 


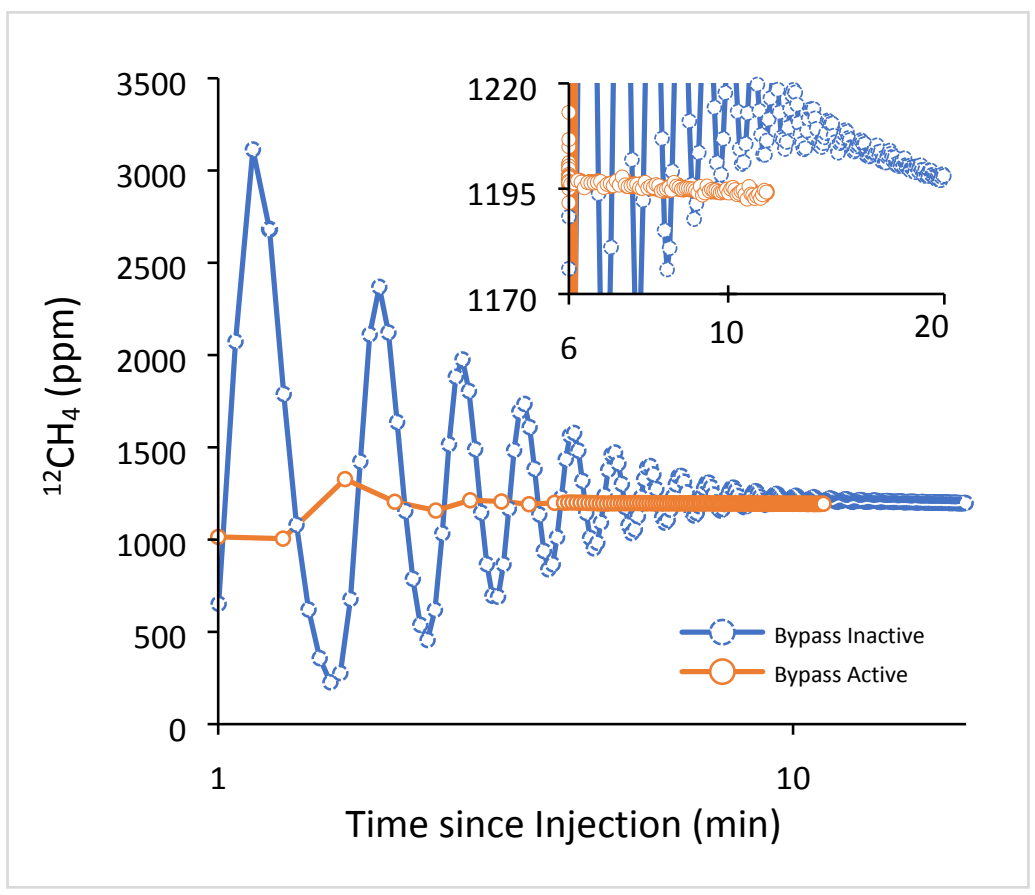

Figure S12. Analysis of samples introduced by Loop B with and without the bypass line activated. The sinusoidal oscillations with the bypass inactive (blue) represents the passage of the sample through the analyzer as it gradually disperses within the system. By contrast, with the bypass line activated (orange) the oscillations are quickly damped and mixing is complete by 6 minutes (see inset). Compete mixing without the bypass line does not occur until $\sim 16$ minutes. 


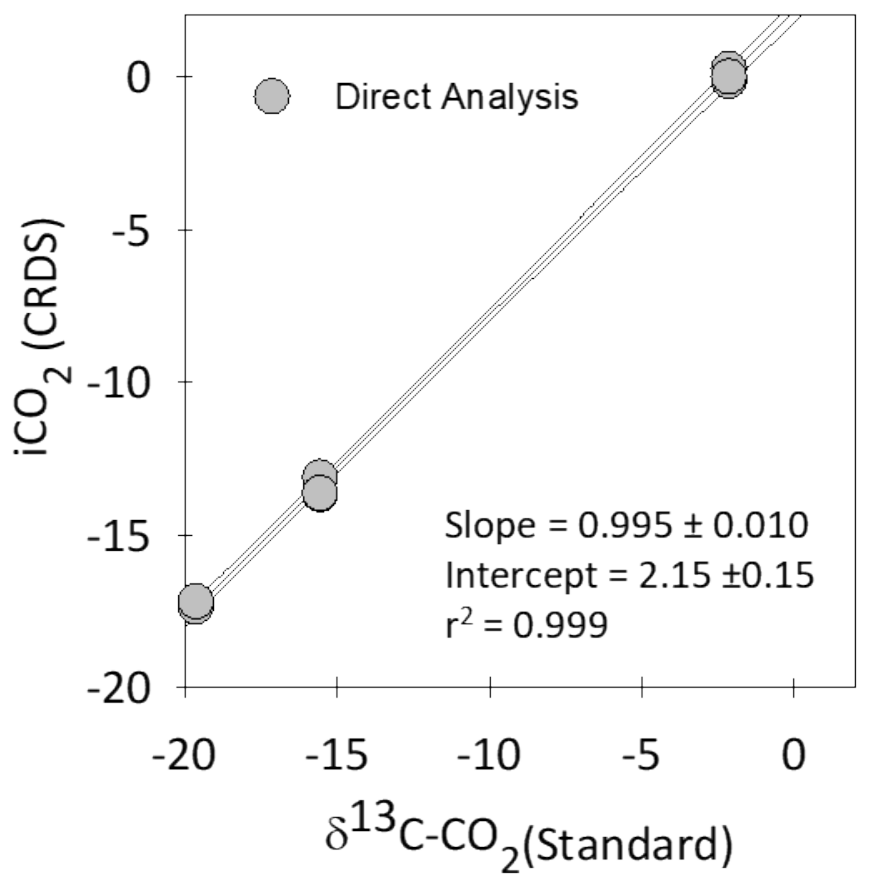

Figure S13. DSIM-CRDS $\delta^{13} \mathrm{C}$ standardization for $\mathrm{CO}_{2}$. The slope and intercept determined from linear regression of all analyses are used to calculate $\delta^{13} \mathrm{C}$ from the instrument output. Outer lines are the $95 \%$ confidence intervals. The $\delta^{13} \mathrm{C}-\mathrm{CO}_{2}$ linear interpolation model is derived from sodium bicarbonate $\left(\mathrm{NaHCO}_{3}\right)$ converted to $\mathrm{CO}_{2}$ by acid hydrolysis. The $\delta^{13} \mathrm{C}$ values of the $\mathrm{NaHCO}_{3}$ secondary standards obtained from commercial sources [-2.15\% (Sigma-Aldrich), -15.57\%o (Arm \& Hammer), and $19.64 \%$ o (Fisher Scientific)] were measured by elemental analysis - isotope ratio mass spectrometry. $\mathrm{CO}_{2}$ was liberated from the $\mathrm{NaHCO}_{3}$ powder by acid hydrolysis with $20 \%$ phosphoric acid injected into an evacuated butyl-rubber stoppered serum vial containing enough powder to generate $1 \mathrm{~atm}$ pressure in the vial. $\mathrm{CO}_{2}$ was diluted with the internal sample loop and external expansion volume with an average precision of $0.20 \%$. 


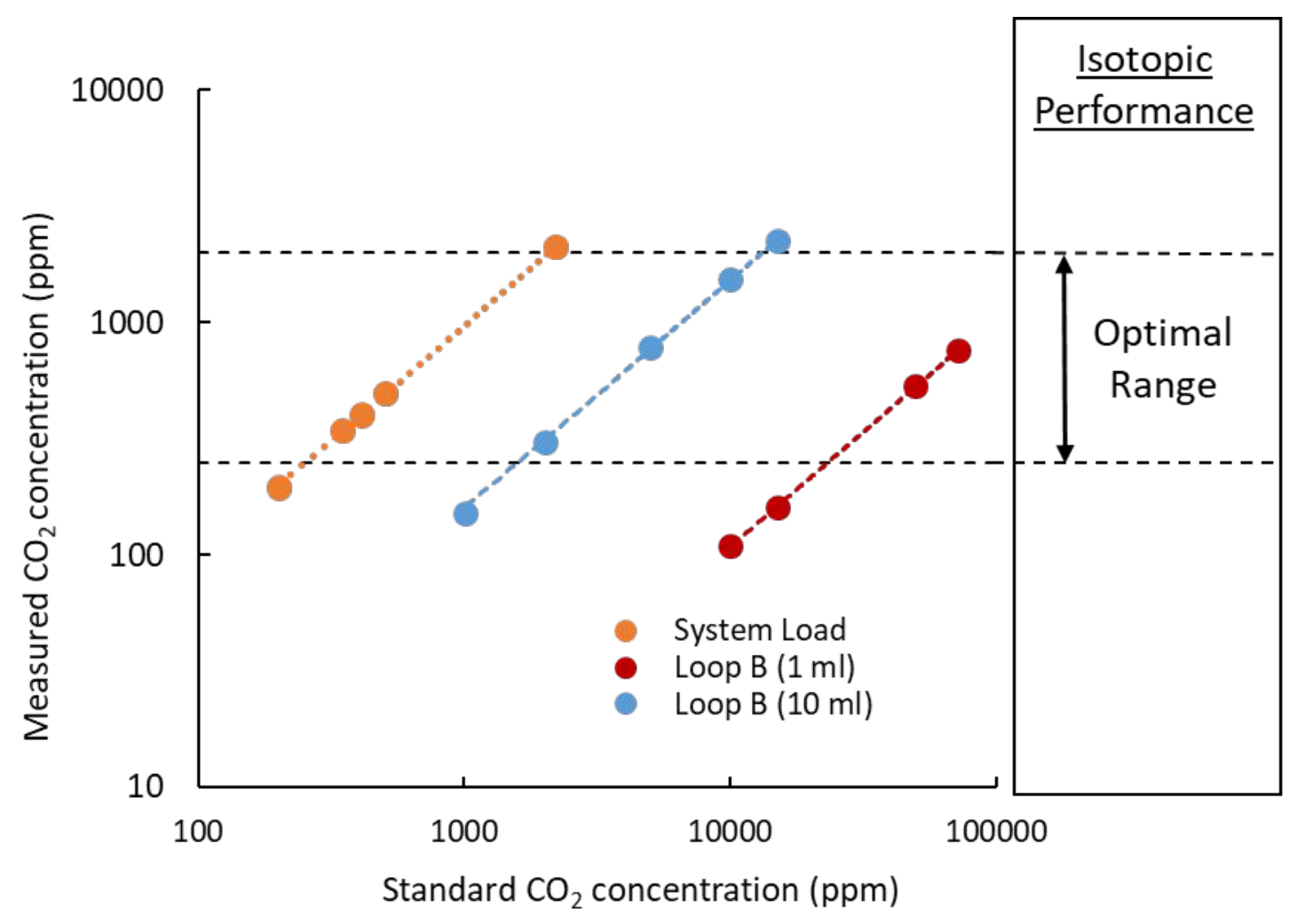

Figure S14. $\mathrm{CO}_{2}$ concentration standardization for DSIM sample introduction modes. Using the range of modes, the calibration is linear from $\sim 100 \mathrm{ppm}$ to $\sim 7 \% \mathrm{CO}_{2}$. The optimal range (200-2000 ppm) is the measured concentration region providing the highest quality $(<1 \sigma) \delta^{13} \mathrm{C}-\mathrm{CO}_{2}$ values. To achieve this range for $\mathrm{CO}_{2}, 1 \mathrm{ml}$ and $10 \mathrm{ml}$ loops were used for Loop B. 

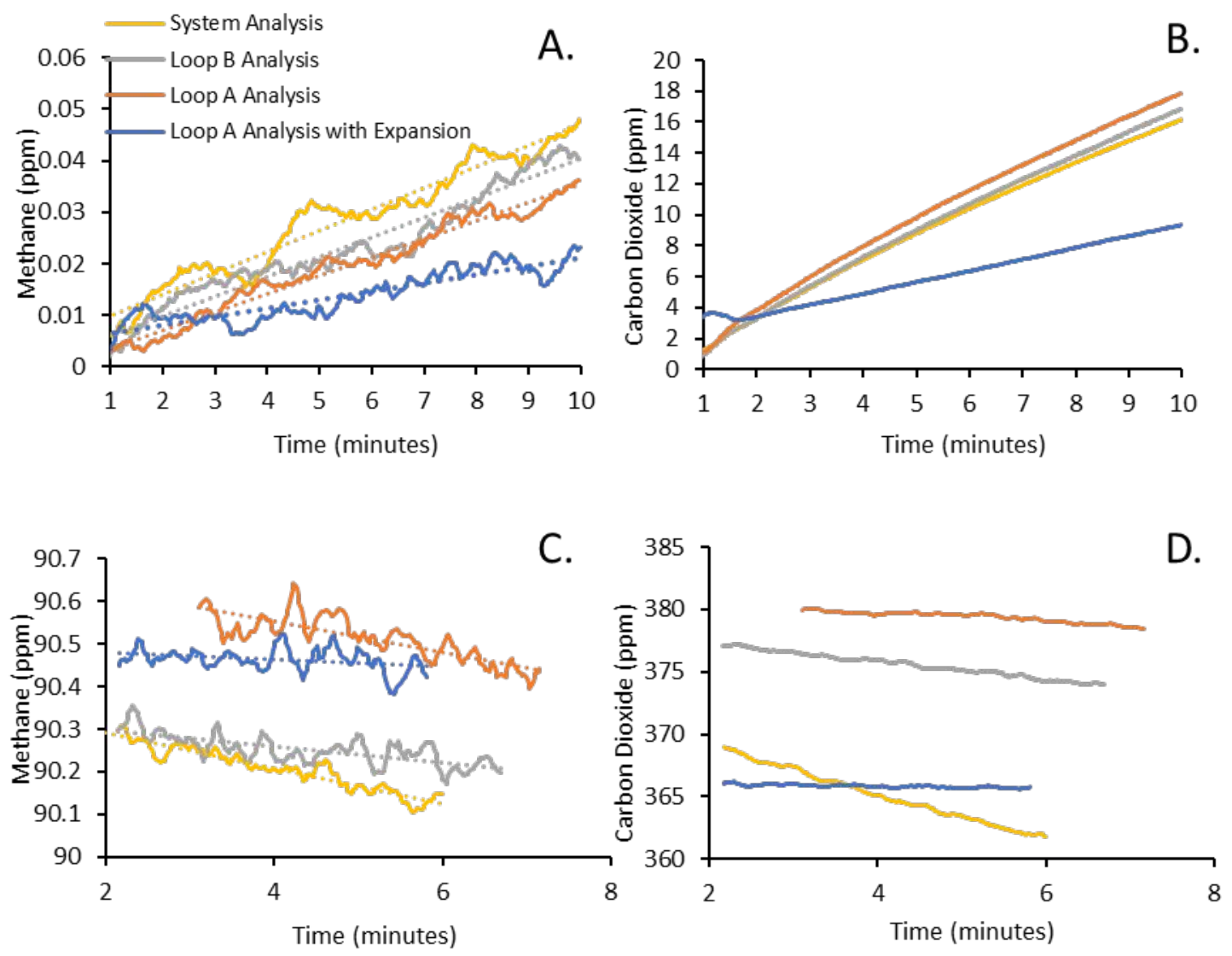

Figure S15: Baseline drift for methane and $\mathrm{CO}_{2}$ for the different DSIM analysis modes. Accumulation of methane (A) and $\mathrm{CO}_{2}$ (B) following System Purge. C. Loss of methane during circulation of a $>90 \mathrm{ppm}$ standard relative to a $1.8 \mathrm{ppm}$ external concentration indicates exchange with air or adsorption of methane to interior components. D. Loss of $\mathrm{CO}_{2}$ for internal concentrations below an external concentration exceeding $400 \mathrm{ppm}$ indicates adsorption of $\mathrm{CO}_{2}$ to internal components, as also reported by Leuenberger et al. (2015). Exchange rates at higher internal concentrations for methane (C) and $\mathrm{CO}_{2}$ (D) differ substantially from the blank values ( $A \& B$ ), but the magnitude of the change is less than $1 \%$ of the measurement (Table S2). Biases related to gas exchange with the atmosphere and/or internal adsorption-desorption effects are accounted for by the DSIM baseline drift correction (see Section 2.3.3). If the correction is > $1 \%$ of a measurement, the system should be evaluated for leakage. 


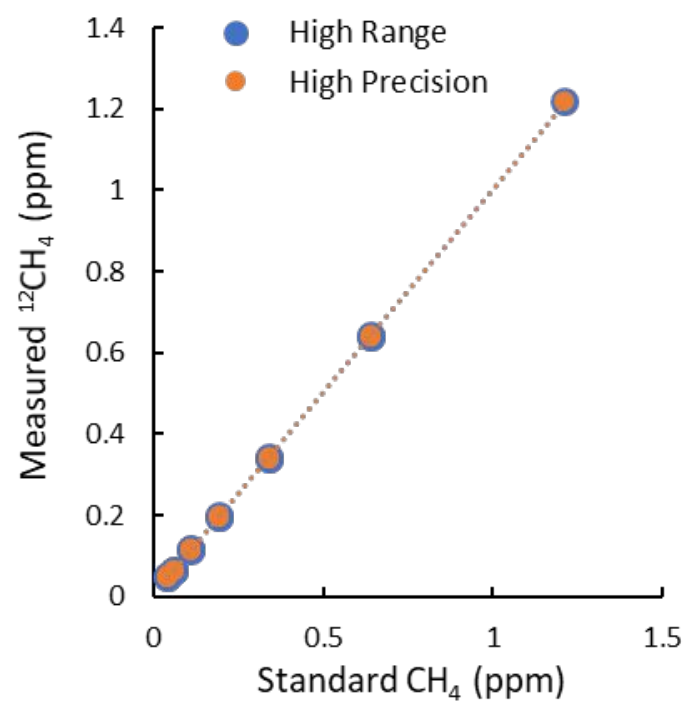

Figure S16. Low methane concentration standardization. Instrument response during System Load remains linear to concentrations at least as low as $40 \mathrm{ppb}$ (or $0.04 \mathrm{ppm}$ ). 


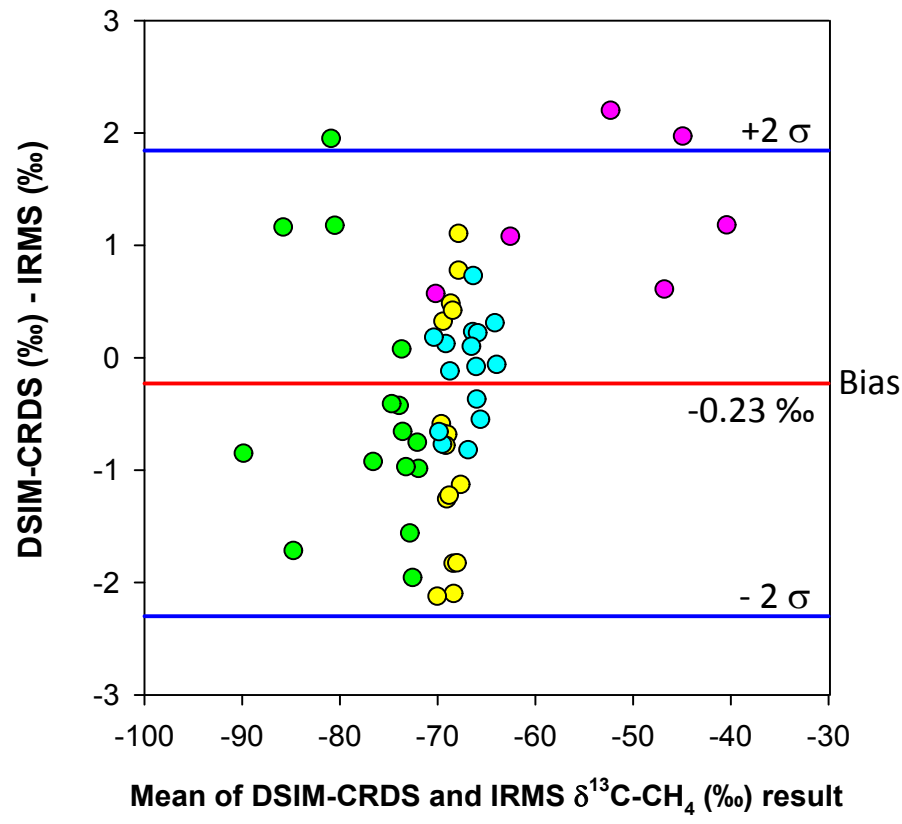

Legend:

Atlantic margin pore water O Atlantic margin water column

O N. Cascadia margin water void gas

O Indian Ocean pressure core

Figure S17. Bland-Altman analysis of DSIM-CRDS and IRMS $\delta^{13} \mathrm{C}_{-} \mathrm{CH}_{4}(\%)$ results. The red line indicates the average offset from a perfect agreement, and the blue lines are the $95 \%$ confidence intervals. 


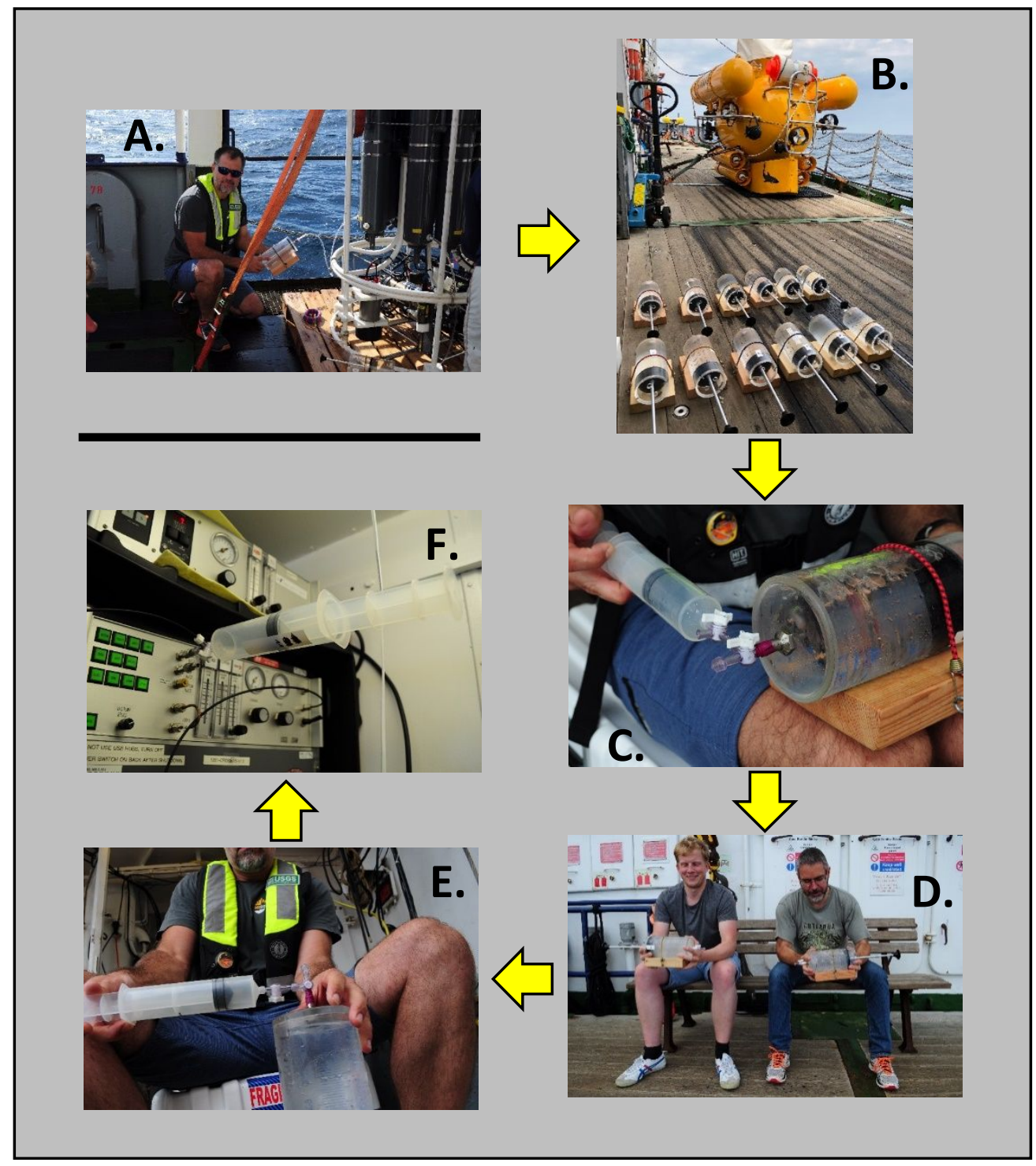

Figure S18. Ocean water sample collection and processing for DSIM-CRDS analysis. A 900 $\mathrm{ml}$ water sample is collected in a $1 \mathrm{~L}$ syringe with a $1 \mathrm{~m}$ section of "bubble" tubing (A). After all the samples are collected (B), $100 \mathrm{ml}$ of analyte-free air is added to each syringe (C) (note horizontal position). Each sample is shaken vigorously for 2 minutes to extract the gas from solution (D). The headspace is withdrawn into a dry syringe (note vertical orientation) (E) and introduced into DSIM in the System Load configuration (F). (Photos by Karen Hissman) 
Table S1. System Configuration Table. 11 operational modes using 8 commands

\begin{tabular}{|c|c|c|c|c|c|c|c|c|}
\hline \multirow[t]{2}{*}{ Operational Mode } & \multicolumn{4}{|c|}{ Function (command) } & \multicolumn{4}{|c|}{ Path (command) } \\
\hline & Purge & Load & $\begin{array}{c}\text { Analyze } \\
\text { (Ana) }\end{array}$ & $\begin{array}{c}\text { Standard } \\
\text { (STD) }\end{array}$ & $\begin{array}{c}\text { System } \\
\text { (SYS) }\end{array}$ & $\begin{array}{c}\text { Loop } \\
\text { A }\end{array}$ & $\begin{array}{c}\text { Loop } \\
\text { B }\end{array}$ & $\begin{array}{c}\text { Expansion } \\
\text { (EXP) }\end{array}$ \\
\hline \multicolumn{9}{|l|}{ Purge } \\
\hline System & $\mathrm{x}$ & & & & $\mathrm{X}$ & & & \\
\hline Loop A & $\mathrm{x}$ & & & & & $\mathrm{X}$ & & \\
\hline Loop B & $\mathrm{X}$ & & & & & & $\mathrm{X}$ & \\
\hline \multicolumn{9}{|l|}{ Load } \\
\hline System & & $\mathrm{x}$ & & & $\mathrm{x}$ & & & \\
\hline Loop A & & $x$ & & & & $\mathrm{X}$ & & \\
\hline Loop B & & $\mathrm{X}$ & & & & & $\mathrm{X}$ & \\
\hline \multicolumn{9}{|l|}{ Analysis } \\
\hline System & & & $x$ & & $x$ & & & \\
\hline Loop A & & & $\mathrm{X}$ & & & $\mathrm{X}$ & & \\
\hline Loop A & & & & & & & & \\
\hline Expansion & & & $x$ & & & $\mathrm{x}$ & & $\mathrm{X}$ \\
\hline Loop B & & & $x$ & & & & $x$ & \\
\hline Standard Analysis & & & & $x$ & & & & \\
\hline
\end{tabular}


Table S2: DSIM-CRDS $\delta^{13} \mathrm{C}_{-} \mathrm{CH}_{4}$ standardization data

\begin{tabular}{lccccccc}
\hline & $\begin{array}{c}\text { Reference } \\
\text { Value } \\
\text { Standard }\end{array}$ & $\begin{array}{c}\text { Loop B } \\
\text { Load/Analysis } \\
(\%)\end{array}$ & $\begin{array}{c}\text { Std } \\
\text { Dev } \\
(\mathrm{n}=3)\end{array}$ & $\begin{array}{c}\text { Direct } \\
\text { Analysis } \\
(\%)\end{array}$ & $\begin{array}{c}\text { Std } \\
\text { Dev } \\
(\mathrm{n}=3)\end{array}$ & $\begin{array}{c}\text { System } \\
\text { Load/Analysis } \\
(\% \circ)\end{array}$ & $\begin{array}{c}\text { Std Dev } \\
(\mathrm{n}=3)\end{array}$ \\
\hline \hline H-iso1 & -23.90 & -31.76 & 0.35 & -31.40 & 0.19 & -31.29 & 0.06 \\
L-iso1 & -66.50 & -73.00 & 0.10 & -72.30 & 0.12 & -72.34 & 0.58 \\
T-is01 & -38.30 & -45.80 & 0.27 & -44.92 & 0.32 & -45.39 & 0.02
\end{tabular}

